\title{
Existem ONGs, ONGs e ONGs. Perspectivas de novas práticas socioespaciais relacionadas à questão da habitação*
}

\author{
Angela Gordilho Souza
}

Arquiteta, professora da FAUFBA

\begin{abstract}
O trabalho em questão compreende a análise de um dos aspectos importantes das novas interações socioespaciais urbanas contemporâneas, qual seja, a atuação das ONGs na questão habitação-ambiente-cidadania e sua relação com o Estado na gestão de políticas públicas e no processo de construção das cidades brasileiras. Aponta para a pluralidade de natureza política desses atores sociais e os alcances socioespaciais, que já se manifestam na prática em diversas áreas de atuação e lugares. Privilegiam-se as práticas que envolvem expectativas da melhoria da qualidade de vida na questão habitacional e ambiental, entendendo-se a moradia enquanto vivências diversas e construção de cidadania, além de abrigo.
\end{abstract}

Para isso, com base na reduzida bibliografia acadêmica existente, reportagens jornalísticas e depoimentos de pessoas envolvidas com esse tipo de organização e atuação, analisa-se a expansão do fenômeno, algumas práticas na América Latina e no Brasil, procedendo-se também a uma leitura dessas manifestações para o caso de Salvador-BA, no que se refere ao relacionamento entre produção cultural e localização espacial em áreas de habitação popular.

\section{Resumo}


Abstract This paper analyses one of the most important aspects of contemporary socio-spacial interaction.

It deal with the role played by ONGs in the housing/environment/ citizenship question, as well as with their relation to the state concerning public policies management and the building of the brazilian cities.

It indicates the political variaty of these actors and their socialspacial reach. Pratices involving hope of improvement in the quality of life are privileged. Housing is understood not only as shelter but as different vital experiences and citizenship construction.

Introdução Nesse final de século, percebe-se uma certa euforia e proliferação acelerada das ONGs no âmbito da sociedade civil, potencializada pelos movimentos ambientalistas e alternativos, e que no Brasil teve o seu auge com as articulações preparatórias para a Conferência Internacional ECO-92. Concomitante à ampliação em número e atuação desse tipo de organização, surgem também fortes críticas, associadas notadamente àquelas de natureza transnacional, que atuam nos países pobres do chamado Terceiro Mundo. Essas são acusadas de levarem modelos de desenvolvimentos e métodos de ação de fora, para serem transplantados em outras sociedades e culturas, com resultados muitas vezes duvidosos.

Sem paixões prós ou contras, porém com intenções de uma leitura crítica, este trabalho busca entender a real natureza e alcance dessa forma de interação social contemporânea, que já consolida algumas práticas em diversas áreas de atuação e lugares. Privilegiam-se, nesta leitura, as atuações que envolvem expectativas da melhoria de qualidade de vida na questão habitacional e ambiental, compreendendo-se o desenvolvimento do homem integral - cidadão e ser - e a moradia contem-porânea num sentido mais amplo, além de abrigo, ou seja, lugar do habitar enquanto vivências diversas, portanto, ambiente socioespacial urbano.

O que são as ONGs

A primeira questão a ser enfrentada diz respeito à qualificação do conceito, usado com uma certa ambigüidade. A sigla ONG Organização não-governamental - tem sido adotada no sentido jurídico mais geral para designar entidades privadas, criadas sem fins lucrativos, voluntariamente, sem acordos contratuais. Essas organizações objetivam o bem comum de comunidades específicas ou da coletividade no seu conjunto, geralmente atendendo a determinados princípios sociais, ideológicos ou de crenças 
religiosas. Assim sendo, estão isentas de impostos, ainda que possam receber doações diversas.

Tomando-se também, por definição, que a sua finalidade não se constitui, explicitamente, em atividades e disputas políticas ou interesses de classes, entende-se que organizações tipo partidos políticos, entidades trabalhistas e corporações afins, ainda que não-governamentais e sem fins lucrativos, não se enquadrariam nesse tipo de agrupamento da sociedade civil.

Por outro lado, há um entendimento mais específico, que relaciona a sigla ONG às organizações transnacionais que atuam em programas e projetos sociais e ambientais em áreas de pobreza, com a cooperação de instituições religiosas, ambientais e filantrópicas, sediadas nos países ricos. Recebem ajuda, em sua maioria, de organismos internacionais como a ONU, OMS e OEA, que funcionam como agências de cooperação, bem como das grandes agências financiadoras de projetos de desenvolvimento, tipo Banco Mundial e Banco Interamericano de Desenvolvimento. Entretanto, para que as ONGs possam existir, não há exigências de vínculos com agências transnacionais; basta reunir um determinado número de associados, fazer a ata da primeira reunião e proceder a um registro em cartório, especificando as suas finalidades e atribuições. Amplia-se, assim, essa designação para organizações nacionais diversas ${ }^{1}$

Portanto, enquanto ator social, não constituem Estado, nem empresa, nem indivíduo, ainda que inseridas na sociedade civil. $\mathrm{Na}$ ação social, tampouco podem ser caracterizadas como eminentemente públicas ou privadas, constituindo-se, pelo seu caráter coletivo, numa espécie de entidades híbridas, semipúblicas, semiprivadas.

Com base nessa definição, percebe-se que a abrangência de entidades civis que atualmente se enquadram nessa categoria social é extremamente ampla. Integram-se no seu conjunto desde entidades técnico-profissionais de assessoria popular, passando pelas associações filantrópicas, abrangendo também organizações populares reivindicativas, preservacionistas e associações culturais. Nesse sentido, podemos afirmar que as "ONGs" existem há muito tempo. Onde está então a qualidade do novo nas chamadas ONGs contemporâneas?

\section{Qualidade do novo e expansão do fenômeno no Brasil}

(1) Segundo entrevistas com integrantes de ONGs, foi declarado que as normas de funcionamento desse tipo de entidade, na constituiçāo brasileira, ainda não se encontram claramente definidas. Atualmente, tramita nos meios parlamentares projeto de lei para regulamentaçāo. 
A nomenclatura foi criada na década de 40 pela ONU para designar entidades não-oficiais, ou seja, não-governamentais, que recebiam recursos de órgãos públicos para executar projetos de interesse social, através de grupos de serviço de ajuda aos processos de desenvolvimento e de reconstrução do pós-segunda guerra. Por isso, também foram denominadas ONGD Organização Não-Governamental de Desenvolvimento.

José Augusto Albuquerque, analisando a natureza política das ONGs e seu impulso na atualidade, identifica a inspiração deste modelo social de organização no associativismo norte-americano, que atribui à iniciativa voluntária do indivíduo a defesa da liberdade e dos direitos. Aponta também para o uso político dessas organizações na guerra fria, com objetivo de difundir os ideais da democracia e da liberdade de mercado, através da ajuda de recursos estrangeiros para influenciar políticas nacionais de países do Terceiro Mundo. Para ele, ao nível mundial, o fenômeno de transnacionalização de opinião pública e de ação política, com as facilidades de comunicação, bem como o refluxo da revolução cultural e política da década de 60 , acabam por beneficiar uma "concepção muito arraigada na elite das sociedades dos países ricos, isto é, de que ninguém melhor do que elas sabe o que é melhor para nós" Por outro lado, "receber dinheiro estrangeiro para influenciar a política nacional deixou de ser razão de condenação ou menoscabo" (Albuquerque, 1995.)

Tilman Evers foi um dos primeiros analistas a tratar a questão da emergência de novos movimentos sociais e estados de ânimo no seio da sociedade civil, ao observar os movimentos políticos alternativos aos partidos e sindicatos na Alemanha dos anos 60 . Surgem num momento de crise econômica, agravamento dos conflitos de política externa e uma crise generalizada de consenso em relação aos padrões tradicionais de legitimidade. Em termos políticos, como registra o referido autor, cresce nessa época um movimento de negação à vasta estrutura tradicional de corporações, através das quais se organizam as várias frações do capital, os sindicatos de trabalhadores, profissionais liberais, etc., para dar lugar a um impulso autogestionário em clara contradição com a abordagem administrativa da social-democracia e com as estruturas corporativas existentes. Emerge, assim, um quarto agrupamento de poder, calcado em idéias ecológicas, antimilitaristas e até antiindustrialistas. Esse é um momento em que aparecem na Alemanha e em outros países da Europa os squatters, 
desempregados sem-teto que invadem edifícios prontos mantidos vazios, bem como os "verdes" ambientalistas pela preservação do planeta, a exemplo do Greenpeace. Esses grupos foram considerados, por algum tempo, como de posições "apolíticas" e "ateóricas", diante do seu não-engajamento com as organizações vinculadas aos processos produtivos. $O$ autor entende que, para esse pensamento alternativo, surgido no refluxo da contracultura, 0 modelo de organização é outro.

Rejeita-se qualquer tipo de estrutura grandiosa, anônima e burocrática, sobretudo o Estado em sua forma contemporânea, procurando-se constituir pequenos grupos baseados em relações interpessoais, ao tempo em que se evitam profissionalizações nos debates, tornando-os acessíveis e claros para todos os integrantes. Em outras palavras "levar a vida pública para a esfera privada" Na sua compreensão dos movimentos alternativos, "o imediatismo autogestionário e o igualitarismo espontaneísta são as tendências emergentes novas, não as únicas, nem mesmo as predominantes" (Evers, 1983: 39.)

Nas últimas décadas, esses movimentos diversificaram-se, cresceram e alastraram-se internacionalmente, concomitante à proliferação das ONGs, como forma alternativa de organização civil, muitas das quais consolidando seus trabalhos junto aos movimentos sociais e políticos. Cresce o número de projetos na esfera da cooperação internacional, observando-se, também, uma maior aproximação com governos, entidades multilaterais e agentes bancários internacionais de financiamentos para o desenvolvimento. Entre 1973 e 1988, apenas 6\% dos projetos do Banco Mundial envolviam ONGs; em 1993, esta proporção aumenta consideravelmente, passando a constituir aproximadamente $1 / 3$ dos projetos aprovados. (The World Bank, 1994, apud Menezes, 1995: 41.)

Na América Latina, nos anos 70, houve uma explosiva emergência de ONGs, abrangendo projetos diversificados tais como assessoria jurídica, defesa e promoção dos direitos humanos, luta pela terra, educação popular, proteção às minorias e à ecologia. No Brasil, embora algumas tenham surgido ainda nos anos 60 , é a partir da década de 80 que tem início um processo de grande expansão na formação de ONGs brasileiras, sobretudo no período da Constituinte, 1986-1988. Nesse momento, despontam com maior visibilidade no cenário político, ao integrar-se aos diversos projetos populares, inclusive na questão da moradia, tendo participado amplamente, do Fórum de Reforma Urbana. (Silva, 1992: 43.) 
Nos anos 90, diversificam-se mais ainda com trabalhos voltados principalmente para educação e meninos de rua. Surgem também com atribuições de suporte técnico-político para as novas administrações públicas. É caso da ONG coordenada pela família do ex-governador de São Paulo Antônio Fleury, denominada "Centro de Estudos Brasil 2000", que, com as contribuições recebidas para promoção de seminários, palestras e desenvolvimento de projetos de interesse social, acaba por bancar os custos da ampliação do seu próprio poder político (Jornal Folha de S. Paulo, 5 maio 1995). Também com vínculos políticos, ainda que indiretos, e com propósitos distintos, foram criadas ONGs, na gestão da ex-prefeita Luiza Erundina, sob a forma de "escritórios técnicos" de apoio ao programa habitacional FUNAPS da prefeitura de São Paulo. Formados por profissionais liberais, principalmente arquitetos, buscam assessorar o movimento popular dos "sem-teto", na perspectiva do fortalecimento da cidadania através da construção da moradia. Já o "Programa de Ação da Cidadania, Contra a Fome, Pela Vida", do Instituto Brasileiro de Análises Sociais e Econômicas - IBASE, coordenado pelo sociólogo Herbert de Souza, "Betinho", surgiu de forma independente para se difundir na sociedade civil. É possível afirmar-se que este também foi encampado politicamente, com o apoio dado pelo governo do ex-presidente Itamar Franco, apoio este que continuou no governo atual, através do programa governamental coordenado pela primeira-dama, a antropóloga Ruth Cardoso, denominado "Comunidade Solidária"

O fenômeno das ONGs no Brasil pode ser medido quantitativamente através da análise comparativa dos dados sistematizados nos últimos anos. O primeiro levantamento foi feito em 1988, pelo Instituto Superior de Estudos da Religião - ISER, quando foram registradas 1.100 ONGs atuando no Brasil (Landim apud Silva, 1993). Desde então, o crescimento em número dessas organizações foi significativo, como apontam dados mais atuais, recentemente publicados pela Revista Veja, que registra um total de mais de 5.000 ONGs existentes no Brasil em 1994. A maioria delas, $40 \%$, está voltada para ecologia, a segunda mais freqüente, $17 \%$, para movimentos populares e as demais, por ordem decrescente, atuam em direitos da mulher e preconceito racial, crianças carentes, AIDS, índios e outros interesses. O volume de dinheiro que movimentam no Brasil também é significativo. Estimase em torno de 700 milhões de dólares por ano, portanto, como informa o referido artigo, maior que a soma do PIB dos estados 
do Acre, Roraima, Amapá e Tocantins. Em relação aos seus quadros de ativistas, nem todos os integrantes de ONGs participam voluntariamente. Calcula-se que 80.000 brasileiros trabalham nessas organizações, sendo que $87 \%$ têm curso universitário e $76 \%$ vivem desse tipo de trabalho. (Revista Veja, 9 fev. 1994.)

$\mathrm{Na}$ região Nordeste, pesquisa desenvolvida por Alexandrina Moura, em 1991, aponta para a existência de 36 ONGs, de diversas categorias, atuando num total de 78 áreas urbanas e rurais, sendo que quase a metade apenas em Pernambuco. Atuando na Bahia, sabe-se que o IX Fórum de ONGs Baianas, realizado em 1994, foi formado por mais de 100 entidades nãogovernamentais. (Jornal A Tarde, 27 jan. 1994.)

Outros indicadores de fortalecimento dessas organizações no Brasil são as iniciativas de congregação entre elas. Surgem nos anos 90, com a criação da Associação Brasileira de Organizações Não-Governamentais - ABONG e a realização dos diversos fóruns de ONGs, contribuindo para a representatividade política dessas organizações, que por sua própria natureza, emergem de forma dispersa e diversificada nos seus objetivos.

Portanto, com base nessa primeira revisão bibliográfica e sistematização de informações, percebe-se que não existe uma perspectiva uniforme de ação para o conjunto das ONGs. Os vieses de atuação são diferentes, bem como as propostas políticas e até mesmo a natureza da sua existência, o que implica em diversos modos e modelos de ação e resultados também diferenciados.

Maria da Glória Gohn, buscando entender a expansão das ONGs como fenômeno social novo na sociedade brasileira, procede a uma classificação que auxilia na compreensão dessa diversidade de ação. Distingue, assim, três campos de atuação: o assistencialismo, que se caracteriza através da filantropia de organizações caritativas; o desenvolvimentismo, que se constitui em programas de cooperação internacional através de agências de fomento públicas e privadas; e o campo da cidadania, organizações criadas a partir dos movimentos que lutam por direitos sociais. (Gohn, 1994: 3.)

Com base nessas leituras, considera-se que as ONGs, especialmente aquelas voltadas para o desenvolvimento, enquanto entidade 
privada trabalhando para o coletivo, sem fins lucrativos, entram no panorama social como alternativa à intervenção governamental nas ações relacionadas à "aliviação da pobreza" Constituindo-se em canais de implantação de programas de desenvolvimento autosustentáveis, representam, portanto, uma saída para o enxugamento dos aparelhos e custos estatais, diante das crises do endividamento público pós-estado do bem-estar, que assim podem dar prioridade de investimentos aos programas de "produtividade urbana".

Analisando as dificuldades atuais do Estado, enquanto instituição pública, frente à globalização financeira e multiplicidade de ONGs, o filósofo Jürgen Habermas, em entrevista recente, afirma que o final do século parece apontar para um esfacelamento sem precedentes do Estado nacional, e mais preocupante, do Estado de Direito (Jornal Folha de S. Paulo, 5 maio 1995). Nesse sentido, o sociólogo Herbert de Souza entende que "público é a palavrachave do momento e contém a solução para um grande debate que atravessa a sociedade brasileira: privatização ou estatização? Mercado ou Estado?" Para ele o conceito democrático de público é o que permite escapar desse falso dilema entre privatização e estatização; o público é o espaço da solidariedade que inaugura a era da cidadania e encerra a era do individualismo e do estatismo. (Souza, 1995.)

Assim, as ONGs têm assumido alguns papéis na intervenção pública, que até há pouco tempo eram praticamente responsabilidade exclusiva do Estado, sem no entanto substituí-lo. Afirmase que, procedendo desta forma, oferecem vantagens de operação em relação ao Estado, através da melhor capacidade de entrosamento com as comunidades atingidas, operações estas que demonstram maior flexibilidade na questão burocrática. Representam, pois, investimentos sociais mais baixos, bem como, maior garantia de continuidade administrativa das ações, características estas que possibilitam produzir resultados mais rápidos, a custos menores, mais eficazes, podendo levar a uma maior credibilidade junto às comunidades-alvo. Se por um lado, apontam-se vantagens nessa nova forma de intervenção em problemas sociais, outros depoimentos levantam e aprofundam alguns questionamentos, os quais serão salientados, mais adiante, na análise de práticas já consolidadas na América Latina e no Brasil.

(2) Ver agenda do Banco Mundial para 
empregos em períodos ditatoriais nos seus países de origem no Terceiro Mundo. Por outro lado, observa-se que, mais recentemente, o número de pessoas envolvidas, com remuneração, tem aumentado. Isto se deve às facilidades de dotação de verbas internacionais para programas sociais alternativos, bem como ao enxugamento de pessoal empregado do Estado, um dos maiores agentes absorvedores desse tipo de mão-de-obra no período desenvolvimentista dos anos 60/70. Esses fatos têm contribuído para a alocação intensiva de profissionais liberais no seio das ONGs, algumas das quais são criadas apenas diante da possibilidade de se obter recursos, com perspectivas de fazer uso para outras finalidades, que não de cunho social, como apontam reportagens jornalísticas recentes ${ }^{3}$.

Em nível de trabalhos filantrópicos e assistencialistas, a Igreja sempre esteve envolvida com atividades caritativas, através de segmentos voluntários da sociedade civil, como senhoras das classes mais abastadas, atuando principalmente junto a crianças e idosos abandonados. As ONGs, não necessariamente, estão ligadas à Igreja, ainda que algumas delas recebam ajuda financeira desse tipo de instituição. Constituem, como visto, organizações da sociedade civil, compostas basicamente por integrantes das classes médias e populares, mesmo quando são criadas por incentivo ou iniciativa de instituições da sociedade.

Assim, o novo nessa modalidade de relação social, como apontam algumas das leituras consultadas, estaria no papel crescente que as ONGs vêm absorvendo, no que se refere à formulação de políticas públicas sociais. Portanto, não estão apenas vinculadas à organização popular e aos movimentos sociais urbanos, mas articulam-se também com setores do governo no atendimento a grupos populares, o que acaba representando uma saída das administrações públicas frente a redução do estado-providência. Para Alexandrina Moura, "as ONGs passaram de uma estratégia defensiva para uma estratégia propositiva” (Moura, 1992: 63.)

$\mathrm{Na}$ análise de Maria da Glória Gohn, "elas introduziram novidades institucionais à medida que se apresentam como executoras de atividades de interesse público fora da máquina governamental, com custos menores e mais eficiência' (Gohn, 1994). Nesse mesmo sentido, Alexandre Menezes vê com perplexidade o futuro da cooperação não-governamental ao aproximar-se dos governos. Para ele, se por um lado, "representa uma possibilidade concreta de
(3) Ver nesse sentido algumas reportagens que acusam o uso ilícito de fundos alocados nas ONGs, a exemplo do que aconteceu em Salvador em 1993. em que a antiga representante do Centro Brasileiro da Infância e Adolescência CBIA foi acusada como responsável por irregularidades (Jornal A Tarde, 21 set. 1993). Por outro lado, o presidente da Associação Brasileira das Organizaçōes Não-Governamentais - ABONG's, sociólogo Jorge Durão, entende que há uma tendência crescente dentro da imprensa brasileira para combater o trabalho das ONGs (Jornal A Tarde, 10 out 1993) 
sobrevivência, (...) por outro lado, a realização de parcerias na esfera governamental traz questões novas para o interior das organizações, de como se envolver preservando a autonomia, ou mesmo de como renunciar, quando em muitos casos representam programas há muito reivindicados pela população" (Menezes, 1994:45.)

No entanto, segundo Rubem César Fernandes, diferentemente dos sindicatos e associações, as ONGs não podem falar ou agir em nome de terceiros. Ainda que trabalhem em benefício de outros, só podem falar por si, não possuindo caráter representativo; a legitimação de suas ações passa por outros aspectos, como os resultados dos trabalhos propostos. Por outro lado, sendo entidades particulares, podem se multiplicar indefinidamente. (Fernandes, 1994; apud Gohn, 1994: 5.)

O novo estaria também no fato de que muitas ONGs buscam despertar e trabalhar com modelos de solidariedade dos cidadãos, com base em pequenas conquistas cotidianas capazes de mudar algumas questões nas comunidades-alvo; trabalho miúdo, fragmentado, com objetivos de melhoria de qualidade de vida. Segundo Gohn, buscam combinar os valores individuais com os valores coletivos e a racionalidade individual com a racionalidade científica, ou seja, desejos e aspirações das pessoas com estudos e análises técnicas dos problemas em questão. Portanto, diferenciam-se das grandes metas de mudanças propostas pelas correntes político-ideológicas de décadas anteriores, bem como da solidariedade assistencialista que, por muito tempo, tem sido pregada pela igreja e outras instituições.

Leituras de práticas na América Latina e no Brasil
Com base nessa abordagem sobre a emergência e natureza das ONGs, questiona-se, a seguir, qual o verdadeiro alcance dos projetos e programas já desenvolvidos por essas organizações; como têm atuado na prática; a quem beneficia de fato; e em relação a habitação, quais as mudanças que promovem ou potencializam.

Na literatura já levantada, percebe-se, no seu conjunto, um teor bastante favorável às possibilidades que surgem a partir da emergência das ONGs no cenário social. No entanto, observase também o surgimento de autocríticas, recomendações, bem como o levantamento de novas questões, que estão presentes em quase todos os textos já consultados, ainda que estes não neguem a sua importância. 
No que se refere ao entrosamento das ONGs com as agências de financiamento, pesam fortes críticas quanto aos resultados obtidos, bem como ao distanciamento entre os discursos e as práticas de combate à pobreza, auto-sustentação e preservação ecológica. Pierre Galand acusa o Banco Mundial de, com a sua aproximação às ONGs, promover uma política de ajuste estrutural, que, ao invés de incidir no alívio da pobreza, agudiza as condições sociais, com a penúria econômica a que estão submetidos os países endividados internacionalmente ${ }^{4}$.

Nessa linha de autocríticas de participantes de ONGs, o depoimento de Alois Moller defende a tese que a relação entre as agências doadoras e os grupos beneficiários de ajuda se assemelham estruturalmente à relação clientelista que sempre predominou na América Latina. Nesse sentido, qualifica, como atores integrantes do que ele denomina mercado de doações, as agências financiadoras internacionais, em seguida, as ONGs, que se propõem a apoiar processos de desenvolvimento e organização popular e, por último, os centros ou organizações populares de todos os tipos. As doações podem ser de três tipos: beneficência, promoção ideológica e de desenvolvimento, motivações estas que quase sempre, segundo o autor, vêm mescladas. Nessa relação, o doador entra com bens materiais, principalmente dinheiro, como também alimentos, ferramentas, etc., enquanto o beneficiário corresponde com um fluxo de bens não-materiais, como, gratidão, obediência, informação, etc. Já os agentes intermediários, as ONGs, agilizam esses processos, na cadeia clientelista. A partir de sua análise, o referido autor chega à conclusão que esse é um mercado incompleto, pouco transparente, de fluxos informais, onde, diferentemente da relação direta existente entre população carente e Estado, não existe o "direito" de receber certo tipo de bens ou serviços. Para ele, no entanto, "como estas organizações são uma realidade palpável e importante, é de suma importância que se consolidem e fortaleçam os espaços da sociedade civil, que se expressam através das organizações populares e de centros de promoção" (Moller,1990: 48.)

Também nesse sentido, incorpora-se a análise que Sônia ArellanoLópez e James Petras fazem sobre a atuação das ONGs como agências de desenvolvimento na Bolívia, ao demonstrarem o caráter de ambigüidade nesse tipo de ajuda. Analisam, entre outras questões, o distanciamento existente entre a definição de critérios para projetos e a participação popular, como também

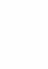 \\ .}

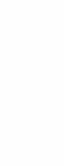


(5) Segundo a referida pesquisa algumas dessas entidades nasceram ligadas à igreja católica, a exemplo da Comissão de Justiça e Paz. Outras constituíram-se como personalidade jurídica própria, caso do Gabinete de Assessoria Jurídica a Organizações Populares. Outros foram articulados ao nível nacional, como a Federação de Órgāos para a Assistência Social e Educacional - FASE. Aos poucos surgiram as ONGs diretamente ligadas ao acesso ao solo urbano, como o Centro de Estudos e Açāo Social CEAS e a Equipe Técnica de Assessoria, Pesquisa e Açāo Social ETAPAS. Ao todo existem 7 ONGs que trabalham com solo urbano, sediadas em Recife. Das 36 ONGs catalogadas no Nordeste em 1991, 15 estão sediadas em Pernambuco (Moura, 1992)

apontam para uma notável falta de entusiasmo dessas agências para participar das mobilizações políticas populares, ocorridas durante a década de 80 . Mais que isso, como intermediários entre o Estado e as agências de financiamento, acabam sendo instrumentos para "minar" as bases institucionais da participação política. Para eles, "isto parece incongruente com uma visão de desenvolvimento como processo que se baseia em apoiar os esforços dos pobres para assumir o controle de suas próprias vidas" (Arellano-López e Petras, 1994: 69,70.)

Para Alexandrina Moura, que desenvolve uma pesquisa sobre ONGs no Nordeste, analisando-as sob a perspectiva de um novo poder emergente, afirma que, de um modo geral, o surgimento dessas organizações tem representado: "a) uma forma alternativa de ação diante de um Estado incapaz de atender às demandas sociais; b) um nível de intervenção entre a esfera governamental e a popular; c) uma intermediação que está sendo reavaliada, pois, ao invés de reforçar a autonomia das bases, em alguns casos termina por fortalecer um padrão de atuação de caráter assistencialista" (Moura, 1992: 56). Observa, também, ao analisar a questão fundiária de acesso ao solo urbano pelas camadas de baixa renda na Região Metropolitana do Recife, que o surgimento de ONGs, desde o início dos anos 60, tem sido fundamental para assessorar os movimentos populares desarticulados e trouxe conquistas jurídicas importantes ao se integrar argumentos sociais aos legais. Para ela, esta convivência tem sido um fator de recriação do próprio direito. Ao implementarem uma estratégia propositiva, acabam interferindo no Plano de Regularização das Zonas Especiais de Interesse Social do Recife - PREZEIS, configurando assim uma proposta de base popular ${ }^{5}$

No âmbito desses prós e contras, percebe-se não só o crescente número de registro de novas organizações, mas principalmente, a emergência cada vez maior de ONGs nacionais, com diversificação de propostas, buscando caminhos próprios e diferenciados dos trilhados pelas transnacionais. Estas, originalmente constituídas com propósitos de ajuda externa para o desenvolvimento de economias atrasadas, atualmente também incorporam novas linguagens e se multiplicam.

Novas leituras em Sobre a presença de ONGs em Salvador, com base na pesquisa Salvador 
observa-se que, praticamente, não foram encontrados textos ou informações sistematizadas sobre sua atuação nessa cidade, à exceção de algumas reportagens jornalísticas. Os indicadores coletados então indicam a existência de 16 entidades filiadas à ABONG, além de outras organizações que atuam independentes, sejam nacionais ou de origem estrangeira sediadas em Salvador ${ }^{6}$. (Jornal A Tarde, 15 maio 1994.)

Na perspectiva de análise deste trabalho, que busca relacionar as ONGs às novas práticas socioespaciais na questão da habitação, outras informações devem ser consideradas. Pesquisa recentemente realizada na Região Metropolitana de Salvador, sobre habitação popular e experiências de intervenção, aponta para novos indicadores relacionados às políticas públicas ${ }^{7}$ Nesse sentido, observa-se que, nos últimos 10 anos, tanto o Estado, através das administrações municipais, vem atuando menos na recuperação física de áreas degradadas, bem como os poucos projetos e programas sociais que, na ocasião, estavam em execução, destinavam-se à promoção de emprego e renda, como cursos profissionalizantes, obtenção de documentos, etc. Ainda assim, os resultados se mostravam insignificantes, sem desdobramentos mais duradouros. Basicamente de cunho político-assistencialista, visavam atender carências de primeira necessidade, como auxílio a desabrigados, obras emergências de mutirão, etc. Quanto aos agentes privados, observou-se que, ainda em número pouco expressivo, aí também vem surgindo ONGs como agentes de intervenção, vinculadas a diferentes entidades e numa perspectiva plural de ação, voltadas inclusive para intervenção no ambiente físico ${ }^{8}$.

Em relação aos movimentos sociais por moradia em Salvador, no início da década de 40 , com a forte crise habitacional que se estabeleceu na cidade, surgiram as primeiras invasões, promovidas por movimentos de ocupação coletiva das massas migratórias, observando-se que apesar das intervenções repressivas do Estado, desde o surgimento do fenômeno até os dias atuais, na sua maioria se consolidaram, fortalecendo os chamados movimentos sociais urbanos (Gordilho-Souza, 1990). Nos anos $70 / 80$, esses movimentos populares ganham maior representação, com a emergência de muitas associações de moradores e com a formação de congregações articuladas a nível local e nacional, como a Federação de Associações de Bairro de Salvador - FABS e, em seguida do Movimento em Defesa dos Favelados - MDF, com atuações significativas, representações
(6) O quadro de entidades filiadas à ABONG, fornecido na reportagem "Lutando por um mundo melhor", compreende: ANAI - Assoc. Nac. de Apoio ao Índio; AEC - Assoc. de Educ. Católica; CEAS - Centro de Estudos e Ação Social; CECUP - Centro de Educ. e Cultura Popular; CESE - Coord

Ecumênica de Serviço; CEADe - Centro Ecumênico de Apoio ao

Desenvolvimento; FASE - Federaçāo de Orgãos para Assist. Social e

Educacional; GAMBÁ - Grupo

Ambientalista da Bahia; GERMEN -

Grupo de Recomposiçāo Ambiental; GAPA - Grupo de Apoio à Prevenção à AIDS; MOC - Movimento de

Organização Comunitária; Olodum Grupo Cultural; AXÉ - Projeto de Defesa e Proteçāo à Criança e ao Adolescente: AATR - Associaçāo dos Advogados dos Trabalhadores Rurais; ISPAC - Instituto de Serviços para uma Açāo

Comunitária; SASOP - Serviço de Assessoria a Organizações Populares Rurais. Estão também listadas como outras: CARITAS DO BRASIL; CPT Comissão Pastoral da Terra; CJP Comissão de Justiça e Paz. (Jornal $\boldsymbol{A}$ Tarde, 15 maio 1994.)

(7) Ver pesquisa coordenada por Angela Maria Gordilho Souza, elaborada para Associação Voluntários para o Serviço Internacional - AVSI, em novembro de 1993.

(8) Este é um primeiro levantamento, não exaustivo, que indica a atuaçāo de novas organizaçōes, quais sejam ANSUR/Ba, Associação Nacional de Solo Urbano/ Regional Bahia - ligada à Arquidiocese de Salvador e voltada para capacitação de lideranças comunitárias e assessoria a projetos urbanos, ex. Projeto Paraguari; AVSI, Associação Voluntários para o Serviço Internacional ligada à Pontificia Universidade Católica de Minas Gerais e ao governo italiano. voltada para recuperaçāo de áreas marginais urbanas, em Salvador, Projeto Novos Alagados; Equipe Urbana da Comissāo de Justiça e Paz - apoio Coordenadoria Ecumênica de Serviços, trabalhos de assessoria juridica: Entidade Francesa Nicholau Catene. voltada para melhoria de moradias em invasão próxima ao aeroporto; Entidade Evangélica, voltada para implantaçāo de lotes residenciais em ParipeNila Cristalina; Fundação José Silveira ligada a Odebrecht, trabalhos educacionais e de habitação no bairro do Calabar (Gordilho-Souza, 1993). 
(9) Alguns estudos já investigam esses processos, sob o ponto de vista de identidade étnica, cidadania, movimentos de bairros, etc. Ver Carvalho (1993), Fischer et al. (1993), Risério (1993), Bahia: Análise \& Dados (1992 e 1994)

(10) No Seminário de Solo Urbano e Moradia, realizado, em Salvador organizado pela Equipe Urbana da Comissāo de Justiça e Paz, em 14 15 de julho de 1995, um dos pontos discutidos foram as diversas questōes que interferem na crise de representatividade das associaçōes de bairro e esvaziamento dos movimentos de cunho reivindicativo por melhorias. Percebe-se uma dissociação entre estas associaçōes e os movimentos culturais que vêm sendo fortemente absorvidos por outras entidades do tipo promotores culturais. No rol de perspectivas de superaçōes, aponta-se para uma maior aproximação entre esses dois movimentos.

(11) O projeto de recuperação de Novos Alagados consta de três etapas. O custo da primeira é de US $\$ 5.000 .000,00$, sendo que US $\$ 4.000 .000,00$ repassados pelo Banco Mundial, e o restante US $\$ 1.000 .000,00$, da AVSI, entidade italiana que iniciou o projeto. Com essa nova parceria, a AVSI fica responsável pela construção de creches e outros equipamentos a serem implantados na área (Jornal $A$ Tarde, 11 mar. 1995)

(12) Projeto Axé, de Salvador, criado pelo um italiano LaRocca, é apontado pela Unicef-ONU como exemplo bem sucedido no Terceiro Mundo. Ampara 2.747 crianças de rua da capita baiana e movimenta um orçamento anual de 800.000 dólares. (Revista Veja, 9 fev. 1994:75) estas que nessa última década enfraquecem, na dinâmica de refluxo do movimento social urbano. Ao lado desses processos, observa-se uma expansão e pluralidade de outras formas de mobilização, de natureza cultural e lúdica, que são diretamente ligadas às influências da cultura africana, de forte tradição em Salvador, e que vêm se afirmando e tornando-se mais visíveis (Carvalho, 1993). Algumas dessas entidades, inclusive, já aparecem enquanto ONGs, como o Olodum, de projeção internacional, observando-se, também, que por trás dessa ascendência estão vários fatores, dentre eles, o fortalecimento de identidade da cultura negra, associado ao crescimento do mercado cultural e turístico ${ }^{9}$ Em relação a essas duas dinâmicas sociais, ainda que contidas nos mesmos espaços comunitários de habitação, observa-se um certo distanciamento entre os chamados movimentos reivindicativos de bairro e os grupos de produção cultural ${ }^{10}$ Nesse sentido, a profusão de organizações de produção cultural, ligadas principalmente à música, percussão e dança indica terem desdobramentos significativos para o espaço do habitar, uma vez que esses movimentos estão localizados, espacialmente, em lugares próprios na cidade.

Por outro lado, algumas intervenções físicas em áreas de habitação, com a participação de ONGs, já foram iniciadas em Salvador, a exemplo daquela que está sendo realizada na localidade conhecida como Novos Alagados, que tem sido objeto de trabalho da Associação Voluntários para o Serviço Internacional - AVSI, visando melhorias para a área e desenvolvimento comunitário ${ }^{11}$ As intervenções físicas propostas, em parceria com o governo do estado da Bahia, demonstram que, nesse caso, as novas qualidades no processo de construção de espaços urbanos habitacionais, localizam-se, principalmente, no fato de que uma ONG permeou o processo, como indutora e intermediadora de políticas públicas, promovendo também, agilidade nas tomadas de decisões públicas, quando anteriormente, as reivindicações se davam, de forma direta, entre o Estado e as populações carentes.

Em Salvador, observa-se ainda que as ONGs existentes dedicadas às questões educacionais e ao menor na rua estão fortemente envolvidas com os movimentos da cultura popular, a exemplo do Projeto Axé e da Banda Mirim do Olodum, que têm tido grande repercussão internacional, diante dos resultados significativos de fortalecimento da cidadania, como também pela inovação de métodos educacionais ${ }^{12}$. 
Este tipo de movimento popular de cunho afro-cultural-musical não é novidade, a rigor, sempre existiu, com forte representatividade, em cidades como Salvador e Rio de Janeiro. Nessas cidades, com formações históricas específicas, ao mesmo tempo que similares, registra-se notoriamente a influência africana, com suas peculiaridades culturais e vocação para manifestações musicais, tendo como palco original o lugar do habitar nas senzalas, morros e favelas, desdobrando-se posteriormente para a cidade.

É evidente que, por trás desse movimento, há um crescente mercado de serviços ávido por lucros que, ao transformar cada vez mais a cultura em mercadoria, acaba por produzir um movimento concomitante de ampliação e redução dos seus valores. Ampliação porque o que antes era reprimido agora é valorizado e difundido, no entanto, manuseado seletivamente, ao tempo em que se reduz a um produto industrial.

Essas são questões que deverão ser melhor analisadas, referenciando-se ao tempo e lugar que são produzidas, para um melhor desdobramento e compreensão do espaço do habitar. Haja vista, por exemplo, que na cidade do Rio de-Janeiro, a mercantilização das escolas de samba, que já ocorre desde meados desse século, foi capitaneada pela contravenção, com apoio das políticas de turismo, exercendo assim uma forte interferência sobre as áreas de favelas. Contribuiu, assim, juntamente com outros fatores, para o controle socioespacial dessas áreas, com desdobramentos na violência que hoje se assiste nessas verdadeiras trincheiras urbanas. Em Salvador, só nas últimas décadas, esses movimentos da produção cultural parecem ocorrer de forma mais organizada e diversa, num processo de emergência aparentemente distinto do que ocorreu no Rio de Janeiro. No bojo desse forte ciclo da indústria do turismo ecocultural, o Estado demostra claramente alavancar esse processo, criando infra-estrutura necessária para os novos empreendimentos e dando apoio aos promotores culturais mais dinâmicos ${ }^{13}$.

Assim, com base nesta pesquisa preliminar sobre a atuação das ONGs no Brasil, e em particular na questão habitacional em Salvador, observa-se que o número de organizações diretamente envolvidas ainda é relativamente reduzido e que estas têm procedido a intervenções de cunho diferenciado. No entanto, os sinais que atualmente se apresentam, seja pelas perspectivas de trabalho das organizações existentes, seja pelo surgimento de novas
(13) Veja nesse sentido as intervenções recentes no Pelourinho Centro Histórico, implantaçāo da Linha Verde e elaboração de plano diretor para esta região do litoral norte. Por outro lado, os grupos afro-culturais como Olodum, Timbalada e outros, de projeção nacional e internacional, também recebem algum tipo de apoio do Estado, ainda que tenham se desenvolvido e sobrevivam de forma independente, constituindo-se, muitos deles, em ONGs. 
Este artigo é resultado de trabalho realizado em julho de 1995 para a disciplina $O$ Estado Capitalista e a Questão Urbana, na FAUUSP, sob a responsabilidade dos Profs. Drs. Celso Lamparelli, Phillip Gunn e Ricardo Toledo Silva, como parte de créditos para doutorado, sob orientaçāo da Profa. Dra. Suzana Pasternak Taschner. organizações e pela saída gradativa do Estado na implementação de políticas habitacionais, demonstram expectativas de continuidade e intensificação desse tipo de ação e atores sociais.

Essas práticas e interações sociais apontam para novos aspectos espaciais, possíveis de leitura através da análise do uso e intervenções nesses espaços, bem como do papel que as ONGs desempenham nessas questões. Nesse sentido, percebe-se que não é possivel fazer uma leitura homogênea dessas organizações, ainda que constituam um fenômeno social novo sob os aspectos aqui analisados. Em franco processo de expansão no seio da sociedade civil, sua natureza demonstra enorme diversidade e perspectivas de desdobramentos que, certamente, irão refletir na construção dos espaços da cidade contemporânea.

\section{Bibliografia}

ALBUQUERQUE, José Augusto Guilhon. ONGs, uma paixão. Folha de S. Paulo, São Paulo, 19 abr. 1995, Caderno 1, p. 3.

ARRELANO-LÓPEZ, Sônia, PETRAS, James. A ambígua ajuda das ONGs na Bolívia. Cadernos do CEAS. Salvador: CEAS, n. 156, mar./abr., 1995.

AVSI - Associação Voluntários para o Serviço Internacional (1993). Relatório final do subprojeto: Salvador e cidades de ocupação contínua na RMS, do projeto experimental: Metodologias e experiências de recuperação de áreas marginais urbanas. Pesquisa coordenada por Angela Maria Gordilho Souza. Salvador: AVSI, 1993. (mimeo.).

BAHIA: ANÁLISES E DADOS. O Negro. Salvador, CEl, v. 3, n. 4, mar. 1994. 5. 1992.

Bahia: indicadores sociais na década de 80. Salvador: CEI, Série Especiais CEI,

BURGESS, Rod. Helping some to help themselves - third world housing policies and development strategies. In: Development planning unit library. Londres: University College London, 199 ?.

CARVALHO, Juvenilda Soares. O governo local e sua relação com o movimento organizado: Engenho Velho da Federação, um estudo de caso. Salvador, 1993. Dissertação (Mestrado) -EAD/UFBa.

MARICATO, Ermínia. Habitação em foco - Estado e movimentos populares organizando uma interlocução. Cadernos do CEAS. Salvador: CEAS, n. 146, jul./ago, 1993.

EVERS, Tilman. De costas para o Estado, longe do parlamento - os movimentos alternativos na Alemanha. Novos Estudos Cebrap. São Paulo, v. 2, 1. p. 25-39, abr., 1983.

FISHER, Tânia, TEIXEIRA, Angela, CARVALHO, Juvenilda, MOURA, Suzana. Redes sociais e associacionismo: um estudo em três bairros de Salvador. Bahia: Análise \& Dados. Salvador: CEI, v. 3, n. 1, jun. 1993.

GAIGER, Luiz Inácio G. Subordinação ou cidadania? Cadernos do CEAS. Salvador: CEAS, n. 157, maio/jun. 1995.

GALAND, Pierre. Não há caminho para humanizar o Banco Mundial. Cadernos do CEAS. Salvador: CEAS, n. 155, jan./fev. 1995.

GOHN, Maria da Glória, SOARES, Suely Galli, MATSUBARA, Marilda, TORRES, Artemis. ONGs - parcerias e educação popular. In: CIDADANIA - Textos. Campinas: GEMDEC/Unicamp, n. 3, dez. 1994.

GORDILHO-SOUZA, Angela Maria. Invasões e Intervençōes Públicas: Uma política de atribuição espacial em Salvador, 1946-1989. Rio de Janeiro, 1990. Dissertação (Mestrado), IPPUR/Universidade Federal do Rio de Janeiro. 
GORDILHO-SOUZA, Angela Maria. (1993) coord. Relatório final do subprojeto: Salvador e cidades de ocupação contínua na RMS - Projeto experimental. Salvador: AVSI, 1993. (mimeo.) (Trabalho encomendado pela AVSI - Associação Voluntários para o Serviço Social.)

JORNAL A TARDE. ONG italiana reforça luta por São Bartolomeu. Salvador, 4 jul. 1995, Caderno 1.

Moradores de Novos Alagados transferidos até final do ano. Salvador, 11 mar. 1995. Caderno 1.

1994. Caderno 1.

Organização amplia poderes de terreiros e blocos afros. Salvador, 22 ago.

Alemanha quer ajudar entidades. Salvador, 8 mar. 1994, Caderno 1

ONGs baianas definem metas e elegem nova coordenação. Salvador, 27 jan. 1994, Caderno 1.

Pobreza do Calabar impressiona os representantes de 17 paises. Salvador, 4 dez. 1993, Caderno 1.

Sociólogo veio para defender as ONGs. Salvador, 10 out. 1993, Caderno.1. . Defesa de entidades complica a ex-chefe do CBIA no estado. Salvador, 21 set. 1993, Caderno 1

Caderno 1.

Projeto Erê tira menores de Novos Alagados das ruas. Salvador, 24 ago. 1993,

Mapa revela situação do meio ambiente no território baiano. Salvador, 16 jul. 1992, Caderno 1.

JORNAL DA BAHIA. Olodum S.A. Salvador, 23 abr. 1994, Caderno Folha.

FOLHA DE S. PAULO (1995). Ex-Primeira-Dama comanda a ONG. São Paulo, 5 jun. 1995, Caderno 1, p. 6.

. Habermas economista. São Paulo, 5 maio 1995, Caderno 1, p. 2.

LÚCIA Maria. Eco URBIS'93 - Seminário Ecologia Urbana. Jornat $A$ Tarde. Salvador, 16 out. 1993, Caderno 1.

MENEZES, Alexandre Queiroz de. Estado, cooperação internacional e construção da cidadania no Brasil. Cadernos do CEAS. Salvador: CEAS, n. 158, jul./ago., 1995.

MOLLER, Alois. Organização popular e clientelismo internacional. Cademos do CEAS. Salvador: CEAS, n. 133, mai./jun., 1991.

MOURA, Alexandrina Sobreira de. Organizações não-governamentais e acesso ao uso do solo na região metropolitana do Recife. Cadernos do CEAS. Salvador: CEAS, n. 147, set./out., 1993.

REVISTA VEJA. O Brasil organizado funciona. Sāo Paulo: Editora Abril, ano 27, n. 6, 9 fev. 1994.

RISERIO, Antônio. A cultura sinaliza o debate sobre modelos de cidade. Bahia: Análise \& Dados. Salvador: CEI, v. 3, n. 1, jun. 1993.

SEMINÁRIO DE SOLO URBANO E MORADIA. 1995. Salvador: Equipe Urbana da Comissão de Justiça e Paz, 14 e 15 de jul. 1995.

SILVA, Ana Amélia. Do privado para o público - ONGs e os desafios da consolidação democrática. Cadernos do CEAS. Salvador: CEAS, n. 146, jul./ago., 1993.

SOLER, Salvador. Movimentos sociais urbanos populares na atual conjuntura - agentes de transformação social?. Cadernos do CEAS. Salvador: n. 154, nov./dez. 1994.

SOUZA, Herbert de. Em nome do bem público. Folha de S. Paulo. São Paulo, 20 jun. 1995, Caderno 1, p. 4.

VAL, Valdicéa do. Lazer e reivindicações sociais estão sempre juntos nos bairros. Jornal $A$ Tarde. Salvador, 17 jun. 1993, Caderno 1.

VIEIRA, Hamilton. Organizaçōes nāo-governamentais - lutando por um mundo melhor. Jornal $A$ Tarde. Salvador, 15 maio 1994, Caderno Lazer \& Informaçāo, p. 13. 